\title{
Article
}

\section{Thyroid Cancer Risk Factors in Children with Thyroid Nodules: A One-Center Study}

\author{
Iwona Ben-Skowronek ${ }^{1, *(\mathbb{D})}$, Joanna Sieniawska ${ }^{1}$, Emilia Pach ${ }^{1}\left(\mathbb{D}\right.$, Wiktoria Wrobel $^{1} \mathbb{1}$, Anna Skowronek ${ }^{1}$, \\ Zaklina Tomczyk ${ }^{1}$, Anna Mlodawska ${ }^{1}{ }^{1}$, Magdalena Makuch ${ }^{1}$, Magdalena Malka ${ }^{1}$, Czeslaw Cielecki ${ }^{2}$ \\ and Pawel Nachulewicz ${ }^{2}$ \\ 1 Department of Pediatric Endocrinology and Diabetology with the Endocrinology and Metabolic Laboratory, \\ Medical University of Lublin, 20-093 Lublin, Poland; joanna.sieniawska@gmail.com (J.S.); \\ emilia.k.pach@gmail.com (E.P.); WiktoriaKW_97@interia.pl (W.W.); ania.skowron97@gmail.com (A.S.); \\ zaklina.tomczyk96@gmail.com (Z.T.); assadana6@gmail.com (A.M.); m.makuch8@onet.pl (M.M.); \\ magdalena.malka@wp.pl (M.M.) \\ 2 Department of Paediatric Surgery and Traumatology, Medical University of Lublin, 20-093 Lublin, Poland; \\ czeslawcielecki@gmail.com (C.C.); nachulewicz@msn.com (P.N.) \\ * Correspondence: iwonabenskowronek@umlub.pl; Tel.: +48-817185440
}

check for updates

Citation: Ben-Skowronek, I.; Sieniawska, J.; Pach, E.; Wrobel, W.; Skowronek, A.; Tomczyk, Z.; Mlodawska, A.; Makuch, M.; Malka, M.; Cielecki, C.; et al. Thyroid Cancer Risk Factors in Children with Thyroid Nodules: A One-Center Study. J. Clin. Med. 2021, 10, 4455. https://doi.org/10.3390/jcm10194455

Academic Editors: Andrzej Lewinski and Renata Stawerska

Received: 22 August 2021

Accepted: 27 September 2021

Published: 28 September 2021

Publisher's Note: MDPI stays neutral with regard to jurisdictional claims in published maps and institutional affiliations.

Copyright: (c) 2021 by the authors. Licensee MDPI, Basel, Switzerland. This article is an open access article distributed under the terms and conditions of the Creative Commons Attribution (CC BY) license (https:/ / creativecommons.org/licenses/by/ $4.0 /)$.

\begin{abstract}
Thyroid nodules are common in the adult population (13\%), but in childhood, they are relatively rarely diagnosed $(0.2-5 \%)$. The risk factors and diagnostic and therapeutic algorithms are well-known and effectively used in adults, but no clear procedures supported by scientific research are available in the pediatric population. Our aim in this study was to identify predictive factors for thyroid cancer in a pediatric population. We retrospectively analyzed 112 children ( 80 girls and 32 boys, aged $0.6-18$ years, with an average group age of $13.4 \pm 4.5$ years) with thyroid nodules who presented or were referred between 2010 and 2021. A total of 37 children qualified for partial or total thyroidectomy. After histopathological nodule examination, the most common cases were benign lesions in 23 patients (57.5\%) and malignant lesions in 14 children (32.5\%). Solitary benign thyroid nodules were found in 16 children $(40 \%)$. Malignancy risk was higher in children with increased nodule diameter (greater than $7 \mathrm{~mm} ; p=0.018$ ) or hypoechogenic lesions in ultrasound $(p=0.010)$, with no correlation between increased blood flow in the vessels and tumor diagnosis. The relative risk of developing thyroid cancer for class III was found to be higher in comparison to adults and 11.1 times higher than for classes I and II combined.
\end{abstract}

Keywords: thyroid nodules; thyroid cancer; risk factors; ultrasound; children

\section{Introduction}

\subsection{Thyroid Cancer Risk Factors}

Nodular goiter is a rare condition in children and adolescents, with a prevalence of $0.2-5 \%$ [1]. However, nodules have a higher risk of malignancy $(25 \%)$ in these age groups than in adults [2]. The risk factors for thyroid nodules are female sex, a positive family history of thyroid disease (e.g., familiar multinodular goiter or familiar nonmedullary thyroid cancer), previous thyroid disease, chronic thyroiditis, autoimmune disease, and taking medication with hormones and steroids [2-6]. Moreover, an elevated thyroid-stimulating hormone (TSH) level and dysfunction of the TSH receptor, sometimes connected to iodine deficiency, can cause thyroid nodules [2,4]. The most important risk factor is exposure to radiation, especially the head and neck, including radiotherapy (e.g., Hodgkin's lymphoma treatment and hematopoietic stem cell transplantation) [2].

A significant increase in the incidence of papillary thyroid cancer was noticed in the areas covered by radiation after the explosion of the Chernobyl Nuclear Power Plant in 1986 and Fukushima in 2011 [7]. Some sources report that nodules with microcalcifications, hypoechogenic nodules, intranodular vascularization, and elevated TSH levels increase the 
risk of thyroid cancer in children [8]. Additionally, thyroid nodules are more often observed in several genetic syndromes such as Cowden syndrome, phosphatase and tensin homolog (PTEN) mutation, McCune-Albright syndrome, Peutz-Jeghers syndrome, Li-Fraumeni syndrome, or Beckwith-Wiedemann syndrome $[2,4,5,9,10]$.

\subsection{Molecular Aspects of Thyroid Cancer}

Thyroid cancer in adults is more locally invasive than in children. Various gene mutations can be found in papillary cancer. For adults, the most common genetic changes are B-Raf proto-oncogene (BRAF V600E) and RAS (a family of small membrane GTPases) point mutations and rearranged in transformation/papillary thyroid carcinomas (RET/PTC) fusions. Human telomerase reverse transcriptase (HTERT) promoter mutations have been observed in adult papillary thyroid cancer (PTCs) and are associated with a more aggressive phenotype [11-16]. Gene mutations and RET/PTC, ETV6-NTRK3, and BRAF fusions (AGK-BRAF and AKAP9-BRAF) are more common in the pediatric population, especially up to the age of 10 years. Research has shown that $50 \%$ of cancers have some kind of gene rearrangement, regardless of radiation exposure [12,13]. The younger the age, the more important fusion oncogenes are in the development of PTC [17]. Medullary thyroid carcinoma occurs in $25 \%$ of the dominant component of hereditary multiple endocrine neoplasia type 2 (MEN2); mutations of the proto-oncogene RET are the most frequently involved in cancer pathogenesis, but there are many other mutation patterns $[13,18]$.

\subsection{Physical Examination}

In most pediatric patients, the disease is asymptomatic when thyroid nodules are detected. Signs of compression such as dyspnea, dysphagia, dysphonia, hoarseness, and pressure or pain in the neck area are extremely rarely observed; if they occur, they indicate local advancement [19].

Attention should also be paid to the symptoms of hyperthyroidism in the patient. The nodules are most often found accidentally by the patients themselves or during a standard physical examination by a doctor [20]. With both viewing and palpation, the first required action is to assess the size and symmetry of the thyroid gland. Physical examination should also focus on the cervical lymph nodes, especially in regions II, III, IV, V, and VI. If nodules are found, it is important to determine their number, approximate size, texture, soreness, and displacement [4].

Oncological anxiety can be caused, especially by hard and non-movable lesions; however, even the smallest palpable nodule should be subjected to further diagnostics [19]. Most lesions smaller than $1 \mathrm{~cm}$ are imperceptible unless they are superficial. Nodules on the posterior wall of the thyroid gland are particularly difficult to access for examination, and even those of considerable size can be easily missed.

\subsection{Diagnostics}

\subsubsection{The Thyroid Gland in Ultrasound Images}

Due to the intensive technical development of ultrasound devices, we are able to detect even small changes (1-2 $\mathrm{mm}$ in diameter) and obtain information about the exact location, echogenicity of nodules, the condition of the surrounding lymph nodes, and the presence of the ultrasonographic features of increased risk of malignancy (Table 1) [21-26].

The patients can qualify for FNAB according to EU-TIRADS classification; however, EU-TIRADS is performed for adult patients but is disputable in children.

Another difference in the pediatric population is the recommendation that all FNABs (fine needle aspiration biopsies) should be performed under ultrasonography guidance. This option is preferred because of the more malignant changes in this age group and because it allows avoiding the difficulty in collaboration with a young patient, with the possible result of nondiagnostic testing and the need for repeated examination [27]. Additionally, the performed FNAB changes the ultrasound image of the lesion, which could adversely affect further imaging observation [5]. 
Table 1. Clinical and ultrasonographic features of increased risk of malignancy [21-26].

\begin{tabular}{|c|c|}
\hline $\begin{array}{c}\text { Clinical Features of } \\
\text { Increased Risk of Malignancy }\end{array}$ & $\begin{array}{l}\text { Ultrasonographic Features of } \\
\text { Increased Risk of Malignancy }\end{array}$ \\
\hline Lymph node metastasis or distant metastasis & $\begin{array}{c}\text { Features indicating the possibility of metastasis } \\
\text { of thyroid cancer to cervical lymph node } \\
\text { microcalcifications, lithocystic character, } \\
\text { hyperechogenicity, round shape, transverse } \\
\text { dimension }>5 \mathrm{~mm} \text {, lack of an echogenic fatty } \\
\text { cavity, marginal or chaotic vascularization of } \\
\text { lymph nodes }\end{array}$ \\
\hline History of neck exposure to ionizing radiation & $\begin{array}{c}\text { Features of infiltration of the thyroid capsule } \\
\text { with or without infiltration of the } \\
\text { surrounding organs }\end{array}$ \\
\hline $\begin{array}{l}\text { History of familial thyroid cancer } \\
\text { (for medullary thyroid cancer) }\end{array}$ & $\begin{array}{l}\text { Presence of microcalcifications in the focal } \\
\text { lesion of the thyroid gland }\end{array}$ \\
\hline Rapid growth of the nodule & Hypoechoic nature of a focal lesion \\
\hline Hard nodule, attached to the surroundings & $\begin{array}{l}\text { Shape of the focal lesion } \\
\text { (longer than the width) }\end{array}$ \\
\hline Diameter of the nodule $>4 \mathrm{~cm}$ & Diffuse margins \\
\hline $\begin{array}{l}\text { Appearance of a thyroid nodule before the age } \\
\text { of } 20 \text { or after the age of } 60 \text { years }\end{array}$ & $\begin{array}{l}\text { Features of increased, chaotic vascular flow } \\
\text { centrally in the lesion }\end{array}$ \\
\hline $\begin{array}{l}\text { Paralysis of the laryngeal nerves, } \\
\text { especially one-sided }\end{array}$ & Solid character of a focal lesion \\
\hline
\end{tabular}

Other imaging tests, such as radiography, computed tomography (CT), magnetic resonance imaging (MRI), or positron emission tomography (PET), do not provide any advantage over ultrasound examination, but their use in looking for metastatic foci may be considered [28,29].

\subsubsection{Hormonal and Immunological Diagnostics}

An indispensable element of diagnosing focal lesions in the thyroid gland is laboratory diagnostics. In the case of nodular goiter, the level of TSH should always be determined, bearing in mind that TSH $>2.5 \mathrm{uIU} / \mathrm{mL}$ is an independent predictor of pediatric thyroid cancer [30].

In the case of lowered TSH levels (or near the lower limit of normal), 99mTc thyroid scintigraphy should also be performed. However, over the past few years, the significance of this test has decreased significantly [20]. Additionally, anti-thyroid peroxidase (TPO) or other antibodies could be marked, calcitonin should be determined in case of suspected medullary carcinoma, RET (gene of tyrosine kinase receptor) mutation could be confirmed to exclude medullary carcinoma before planned surgery, or elastography could be performed before the planned FNAB to select the correct puncture site [29].

\subsection{FNAB Results and the Choice of Further Treatment}

According to the 2015 recommendations of the American Thyroid Association (ATA) regarding the management of children with thyroid nodules and differentiated thyroid cancer, the ultrasound-guided fine needle aspiration biopsy (US-FNAB) result is a decisive factor for further treatment.

\subsubsection{Histopathological Diagnosis and Further Management}

The treatment of thyroid tumors depends on the histological type. Among the pediatric population, PTC is the most common, followed by follicular thyroid cancer (FTC), medullary thyroid cancer (MTC), and anaplastic cancer, among others [6]. 


\section{Benign Thyroid Nodule}

In the case of benign thyroid nodules, the 2015 ATA guidelines recommend repeating the ultrasound in 6-12 months and reassessment. Surgical procedures, e.g., lobectomy, should be included if, due to the size of the nodule, compressive symptoms are present or because of cosmetic reasons or the patient's / parents' desire. If the nodule is stable in the reassessment, the next US should be repeated every 1-2 years, but if the nodule is growing or other suspicious symptoms are present in the US, FNAB or surgery should be performed. Levothyroxine suppressive therapy reduces the nodule size and decreases the risk of new lesions, but data about the long-term safety profile of this treatment method are ambiguous. If a pediatric patient has an autonomous thyroid nodule, considering the risk of DTC, which is incidentally found in up to one-third of patients with autonomous thyroid nodules, surgical resection is the procedure of choice. There is no information available on the safety and efficacy of other treatments in the pediatric population. In the absence of clinical symptoms, surgery can be postponed by performing FNAB if the nodule has PTC features [5].

\section{Malignant or Suspicious Lesions}

An FNAB result indicating a malignant or suspicious lesion is an indication for a surgical procedure, most often total thyroidectomy (TT), which is excision of the right and left lobe, pyramidal lobe (if present), and isthmus. If the nodule is benign after histopathological examination, the level of thyroid hormones should be monitored, and a clinical evaluation of the patient should be performed; if a malignant change is demonstrated, the procedure depends on the type of neoplasm [5].

When PTC is detected in a patient, TT is usually recommended. For a small, unilateral tumor, near-TT may be considered, leaving $<1-2 \%$ of the thyroid tissue around the recurrent laryngeal nerve and/or upper parathyroid glands to avoid damage to these structures [5]. The procedure after FTC detection does not differ from PTC treatment: the recommended treatment is lobectomy with isthmusectomy. In the case of a tumor larger than $4 \mathrm{~cm}$ infiltrating blood vessels, TT is recommended due to the higher risk of metastasis [5].

According to the 2015 ATA guidelines, the FNAB result, meaning MTC with a calcitonin level below $500 \mathrm{pg} / \mathrm{mL}$, is an indication for TT, in some cases in combination with external beam radiotherapy. In the case of calcitonin levels above $500 \mathrm{pg} / \mathrm{mL}$, the presence of distant metastases should be assessed; if they are absent, proceed as in the case of calcitonin levels below $500 \mathrm{pg} / \mathrm{mL}$, but if they are present, TT should be performed, regional disease treated, and systemic therapy started with drugs with thyroid kinase inhibitor (TKI) groups [31].

Prophylactic TT is recommended in patients with MTC who have an RET germline mutation and the resulting multiple endocrine neoplasia type 2A (MEN2A) or multiple endocrine neoplasia type 2A (MEN2B) syndrome [31].

\subsubsection{Assessment with TBSRTC and Further Treatment}

FNAB results are reported according to the Bethesda classification, and the ATA guidelines recommend the use of the same system for describing pediatric thyroid cytology as that used for adults [32].

The risk of thyroid nodule malignancy estimated by the FNAB score and the Bethesda classification plays a key role in selecting further treatment. In the adult population, including NIFTP for malignant tumors, class I (unsatisfactory or non-diagnostic biopsy) is associated with a malignancy risk of $5-10 \%$, class II (benign lesion) with a risk of $0-3 \%$, class III (AUS/FLUS) with a risk of $6-30 \%$, class IV (FN or SFN) with a risk of $10-40 \%$, class V (suspicious for malignancy) with a risk of $45-75 \%$, and class VI (malignant) with a risk of $94-99 \%$ [33].

If the biopsy result is unsatisfactory or non-diagnostic, which means class I Bethesda, US and FNAB should be repeated within 3-6 months. When the nodule is stable in 
the examinations and the FNAB result shows a benign lesion, ultrasound follow-up is recommended for 6-12 months, whereas evidence of abnormalities in these tests is an indication for surgery [5].

In the case of Bethesda class II (benign lesion), clinical and ultrasound follow-up is recommended [33].

The management of the TBSRTC III category, AUS/FLUS, is not as obvious as for the borderline classes of this system due to the intermediate risk of malignancy and the associated diagnostic uncertainty, along with difficulties in predicting the patient's prognosis. Management suggestions include replication of FNAB, molecular testing, or lobectomy, depending on the clinical condition [33].

A similar problem also occurs with class IV, which describes a follicular neoplasm or suspicious follicular neoplasm. The risk of malignancy of these lesions is so high that choosing the right treatment is a priority. Surgical procedures (hemithyroidectomy or lobectomy) supplemented with molecular testing are usually recommended [33].

In class $\mathrm{V}$, in the case of lesions suspected of being malignant, and in class VI (malignant nodules), the procedure is usually an operation: lobectomy or near-TT [33].

The above practices for each class of TBSRTC apply to adults but should be adapted for the assessment of pediatric patients.

\section{Patients, Materials and Methods}

A retrospective analysis of 112 patients with a thyroid nodule who presented or were referred to our center between 2010 and 2021 was performed. The medical records of patients including preoperative, intraoperative, and postoperative data were reviewed. We analyzed the following information: age, sex, attending illness, clinical symptoms, physical examination, family history, thyroid ultrasonography, FNAB result, surgical procedures, histopathological findings, complications, and follow-up findings. The diagnostic pathway for patients with thyroid nodules is shown in Figure 1.

In all patients, TSH, free thyroxin (Elisa ABBOTT), thyroid peroxidase autoantibodies (TPO Ab), and thyroglobulin autoantibodies (Tg Ab; Elisa DAKO, Copenhagen, Denmark) were determined annually. Hashimoto's thyroiditis was diagnosed in children with positive tests for TPO Ab and $\mathrm{Tg} \mathrm{Ab}$ at normal or decreased free thyroxin levels.

Autoantibodies were analyzed in children with decreased TSH and increased free thyroxin; elevated TPO Ab and $\mathrm{Tg} \mathrm{Ab}$ indicated Hashitoxicosis, a form of Hashimoto's thyroiditis. Elevated thyroid stimulating immunoglobulin (TSI) antibodies (RIA BRAHMS, Berli, Germany) were used to diagnose Graves' disease. In all patients, the calcitonin level in serum was determined.

Thyroid ultrasonography was performed using a Siemens Sonoline Elegra. Highresolution linear transducers $(7.5 \mathrm{MHz})$ were used. The protocol includes two-dimensional (2D) gray-scale imaging of the right and left lobes, isthmus, and, if present, the pyramidal lobe, with sagittal and transverse views. The thyroid sonographic reports included the thyroid's position, shape, size, content, echogenicity, and vascular pattern. Three linear dimensions were measured for each lobe: the length and anterior-posterior diameters of each lobe in the sagittal view, and the width in the transverse view. The volume of each lobe can be automatically calculated after recording the abovementioned three linear dimensions using the ellipsoid equation with a correction factor: $\mathrm{V}$ (volume in $\mathrm{mL}$ ) $=\mathrm{L}$ (length in $\mathrm{cm}) \times$ A-P (anteroposterior diameter in $\mathrm{cm}) \times \mathrm{W}($ width in $\mathrm{cm}) \times 0.523$. The nodule dimensions were measured: length, height, and width. Every thyroid nodule was measured and assessed individually, including its location, size, internal structure, and vascularity by color Doppler. 


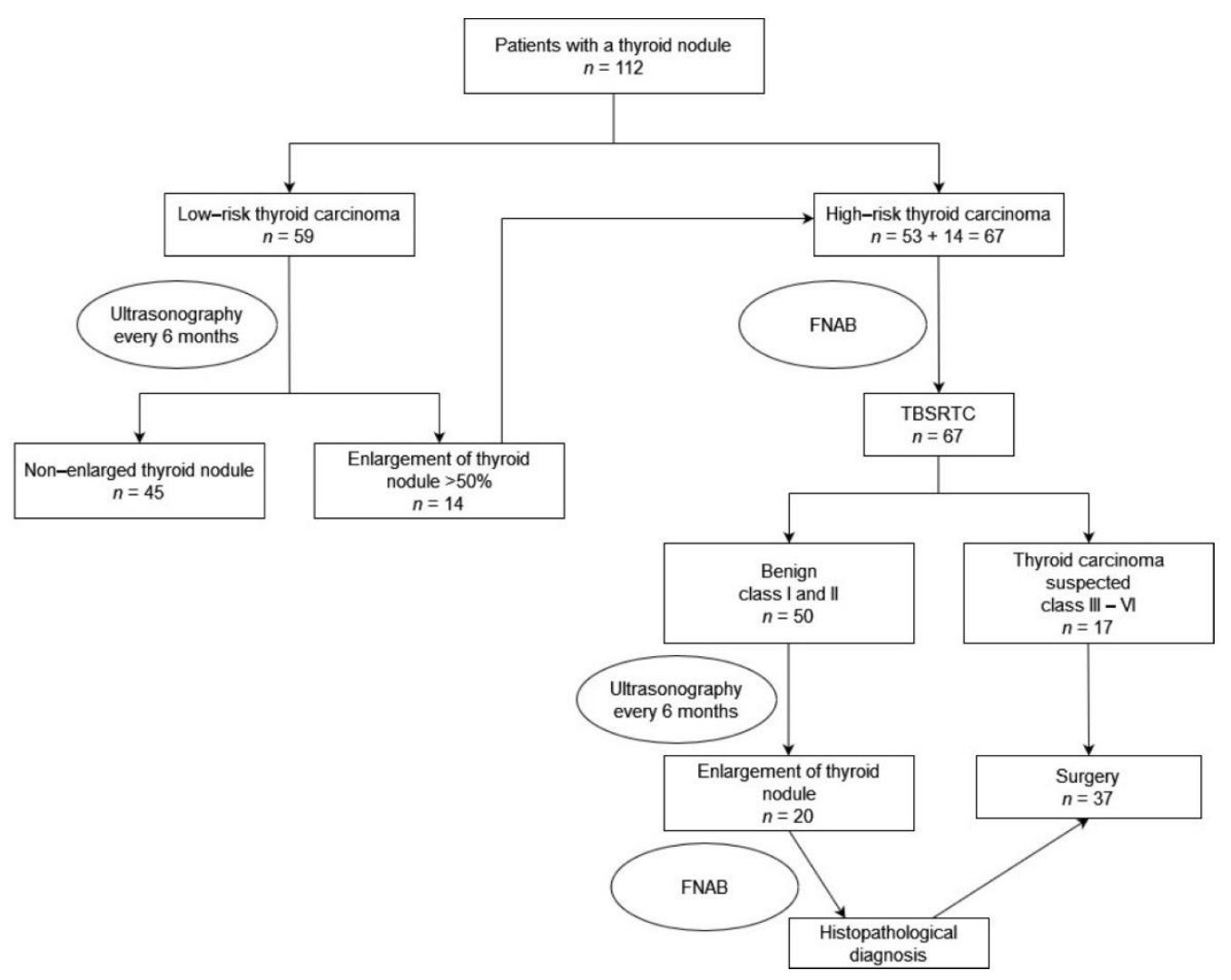

Figure 1. Diagnostic pathway for patients with thyroid nodules. FNAB- Fine needle aspiration biopsy; TBSRTC-The Bethesda System for Reporting. Thyroid Cytopathology.

\section{Statistical Methods}

To verify the hypotheses for qualitative variables, a chi-squared test, a chi-squared test with Yates's correction, or Fisher's exact test was performed, as appropriate. In the case of quantitative variables, due to the patient groups (group with a histopathological result of 0 and a histopathological result of 1) being asymmetrical, the non-parametric Mann-Whitney U-test was used to check for significant statistical differences between the groups. The level of statistical significance was set to $p=0.05$. For variables such as length, height, width, and volume of tumor, ROC curves were used to assess the quality of the quantifiers. The value of the AUC and the optimal cut-off point were determined in each case.

Statistical analyses were conducted using the Statistica 13.3 program.

Before commencement of the investigations, all parents signed an informed consent form. The investigation was accepted by the local Ethics Committee at the Medical University in Lublin.

\section{Results}

Retrospectively, we investigated 112 children ( 80 girls and 32 boys) diagnosed with thyroid nodule in our center between 2010 and 2021. Visible or palpable swelling in the neck was the presenting admission symptom in the 112 patients $(100 \%)$, among which 60 patients had a solid thyroid nodule in the right lobe, 35 patients had a solid thyroid nodule in the left lobe, 16 patients had multiple thyroid nodules, and only one patient had a solid nodule in the thyroid isthmus. There were no significant differences in the malignancy rate due to nodule localization, but the number of multiple thyroid nodules was slightly higher in the low-risk group.

We identified an increased risk of thyroid carcinoma due to a positive family history in 20 patients $(17.86 \%)$. A total of 17 patients had a history of thyroid diseases: Hashimoto thyroiditis in 15 patients $(13.39 \%)$ and Graves' disease in three patients $(2.68 \%)$. Two pa- 
tients $(1.78 \%)$ had a history of neuroblastoma and had been treated with radiotherapy to the neck. There was no significant association between a positive history of radiotherapy $(p=0.117)$, a positive family history $(p=0.11)$, and autoimmune thyroid diseases (AITDs) $(p=0.508)$ with Graves' disease $(p=0.278)$ or Hashimoto thyroiditis $(p=0.936)$.

We observed 59 children with a low risk of thyroid carcinoma without surgical intervention, which were named the low-risk group. Patients with a low risk of thyroid carcinoma were followed by ultrasonography and laboratory tests for 6-60 months.

The mean age of all patients was $13.4 \pm 4.5$ years ( $0.6-18$ years). The mean age of the highand low-risk groups was $14.7 \pm 3.0$ years (2.8-17.9 years) and $12.5 \pm 5.2$ years (0.6-8.1 years), respectively. The malignancy risk was slightly higher in older children $(p=0.047)$ (Figure 2).

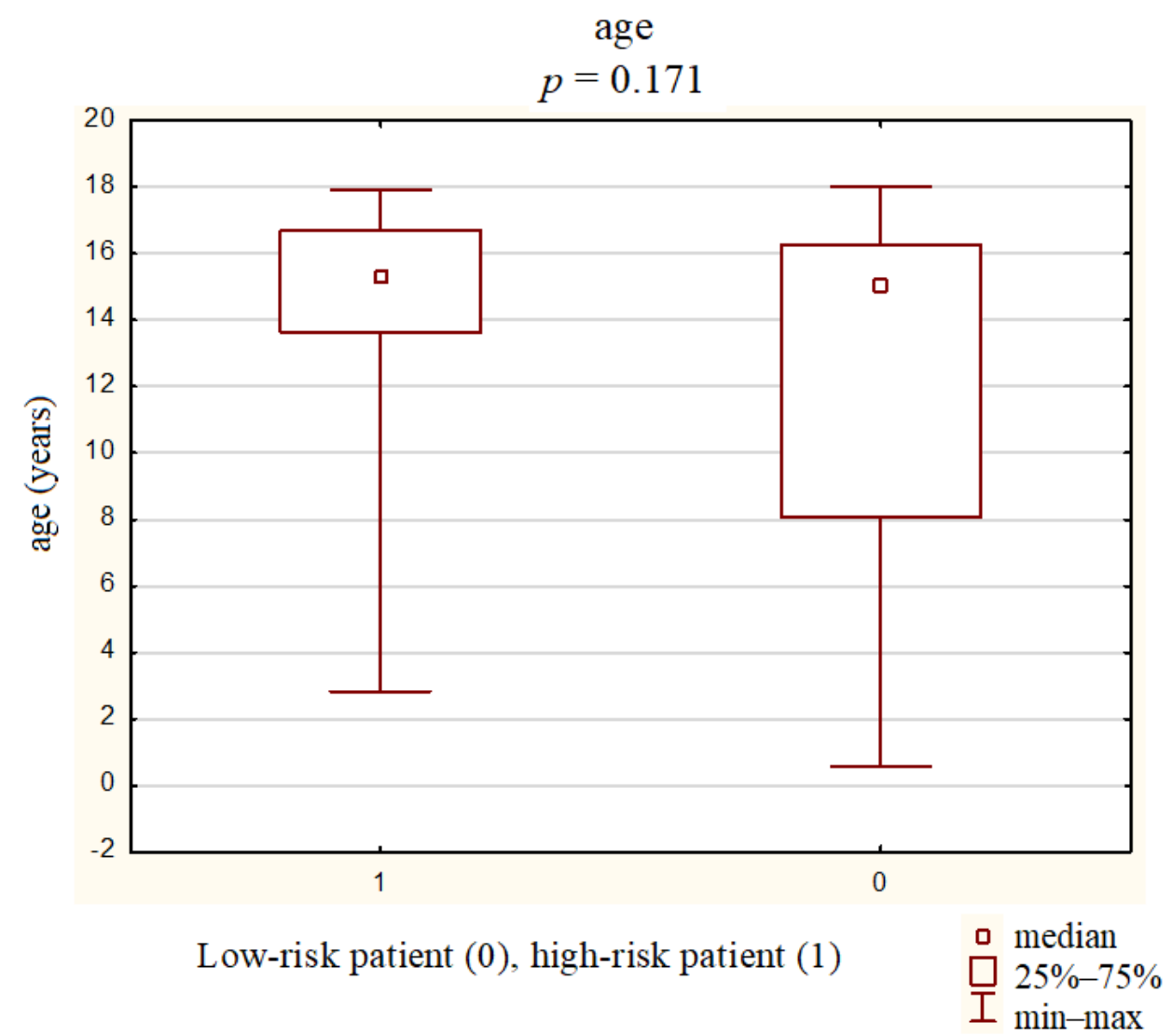

Figure 2. Mean age of the groups with a high risk and a low risk of thyroid cancer.

There was no significant association with patient sex. Most patients were girls in both the low-and high-risk groups (Figure 3).

Thyroid ultrasonography was performed on all patients. The mean nodule volume size of the high-risk group and the low-risk group was $4.7 \pm 6.5 \mathrm{~mL}$ and $3.5 \pm 6.5 \mathrm{~mL}$, respectively. The mean nodule volume was not significantly larger in the high-risk group $(p=0.1456)$.

In the low- and high-risk groups, the mean height, length, and width of the nodules were measured: $9.9 \pm 8.3$ and $14.1 \pm 8.0,13.7 \pm 10.5$ and $17.6 \pm 10.1$, and $15.1 \pm 12.4$ and $19.0 \pm 14.8$, respectively.

The malignancy risk was higher in children with a greater nodule height $(p=0.018)$ (Table 2).

Analysis of the ROC curves of the length, height, width, and volume of nodules in patients indicated that the pivotal dimension was the height of the nodule. In children whose histopathological examination revealed a malignant lesion of the thyroid, a statistically significantly greater nodule height was found compared to benign lesions. Nodules longer than $7 \mathrm{~mm}$ were statistically significantly diagnosed as thyroid cancer (Figure 4). 


\section{Division by sex - diagnosis in histopathological examination $p=0.599$}

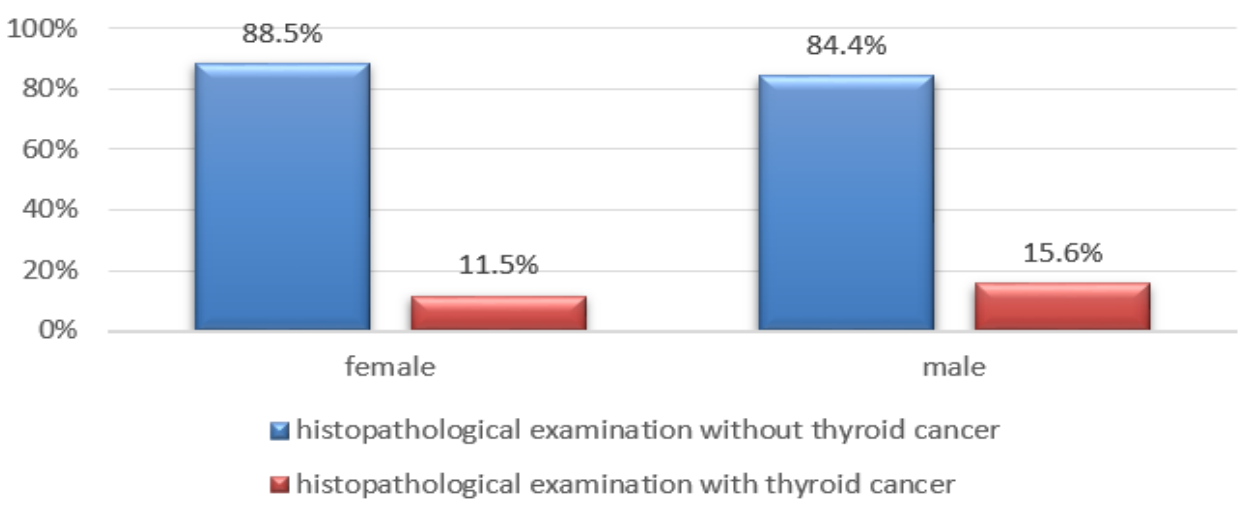

Figure 3. Division by sex: diagnosis based on histopathological examination.

Table 2. Dimensions of the thyroid nodules in patients without and with thyroid cancer (MannWhitney U-test, significance $p<0.05)$.

\begin{tabular}{cccc}
\hline Nodule Dimensions & $\begin{array}{c}\text { Patients without } \\
\text { Thyroid Cancer } \\
\text { Mean } \pm \text { SD }\end{array}$ & $\begin{array}{c}\text { Patients with Thyroid Cancer } \\
\text { Mean } \pm \text { SD }\end{array}$ & $p$ \\
\hline Length $(\mathrm{mm})$ & $13.7 \pm 10.5$ & $17.6 \pm 10.1$ & 0.090 \\
\hline Height $(\mathrm{mm})$ & $9.9 \pm 8.3$ & $14.1 \pm 8.0$ & 0.018 \\
\hline Width $(\mathrm{mm})$ & $15.1 \pm 12.4$ & $19.0 \pm 14.8$ & 0.296 \\
\hline Volume $\left(\mathrm{mm}^{3}\right)$ & $4.7 \pm 6.5$ & $3.5 \pm 6.5$ & 0.146 \\
\hline
\end{tabular}

The hypoechogenicity of nodules or focuses was noted in $78.6 \%$ patients with thyroid cancer in ultrasound imaging and was significantly correlated with a final diagnosis $(p=0.010)$. The comparison of hypo- and hyperechogenic ultrasound of nodules is presented in Figure 5.

We did not observe any statistically significant correlation between increased blood flow in the vessels of the nodules and final cancer diagnosis in the histopathological examination. A comparison of blood flow in power Doppler ultrasonography is presented in Figure 6.

Microcalcifications on ultrasonography $(<1 \mathrm{~mm})$ were observed only in three patients in the high-risk group, finally diagnosed as thyroid papillary carcinoma, and in four patients, diagnosed as benign follicular nodules.

In 67 patients (59.82\%), FNAB was performed. In 47 patients (70\%), the FNAB result was benign (TBSRTC class II); in three patients $(4.47 \%)$, non-diagnostic TBSRTC class I; in nine patients $(13.43 \%)$, suspicious (TBSRTC class III); in eight patients (11.94\%), malignant (TBSRTC class IV). For three patients $(4.5 \%)$, the result was TBSRTC class V; TBSRTC class VI, for one patient (1.5\%) (Figure 7).

A surgical procedure was performed in 37 patients (33.04\%). A total of 12 patients $(10.71 \%)$ underwent local excision of the suspected nodules, lobectomy was performed in 17 patients $(15.17 \%)$, and TT was performed in eight children (7.14\%). In three children $(2.68 \%)$ with a high risk of thyroid carcinoma and a suspicion of metastases in the lymph nodes, frozen section examination was performed of the lymph nodes.

After histopathological nodule examination, the cases were benign lesions in 23 patients $(62.16 \%)$ and malignant in 14 children (37.84\%). Solitary benign thyroid nodules were identified in 16 children (40\%). Multinodular goiter was diagnosed in three patients $(7.5 \%)$; two children (5\%) had Hashimoto thyroiditis or Graves' disease. Of the malignant, the most 
common were papillary carcinoma (nine patients), follicular carcinoma (three children), and poorly differentiated thyroid carcinoma (one patient) (Table 3).

ROC diagram

Youden's index $=0.42$

Proposed cut-off point: height $=7.00 \mathrm{~mm}$

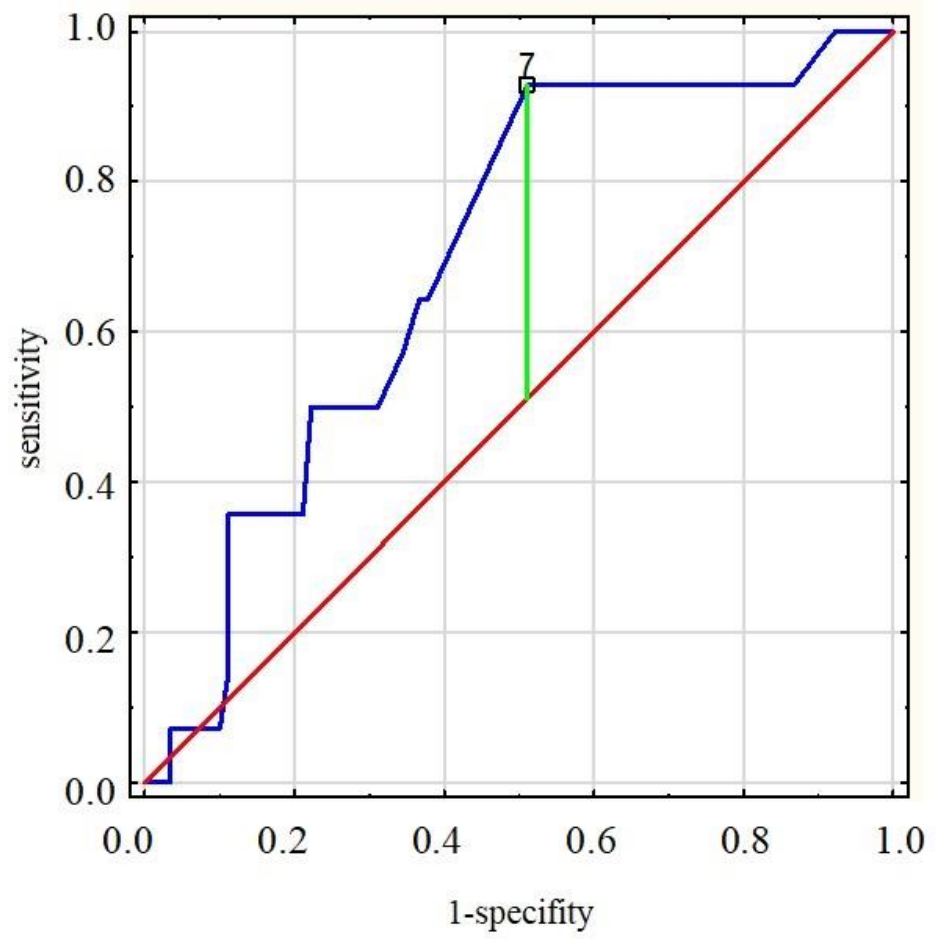

Figure 4. ROC diagram (receiver operating characteristic curve): nodule height and the risk of malignancy.

\section{Echogenicity of the nodules in ultrasound imaging$$
p=\mathbf{0 . 0 1 0}
$$

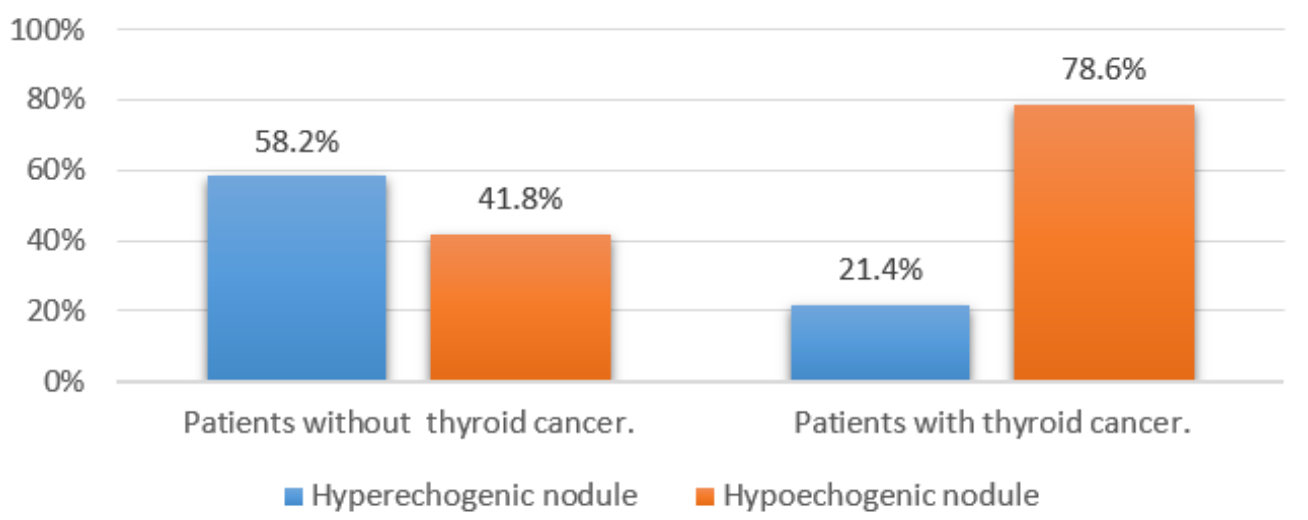

Figure 5. Echogenicity of the nodules in ultrasound imaging.

The sensitivity of the FNAB was $67 \%$ and the specificity was $90.2 \%$.

Some interesting data concern the frequency of diagnosis of thyroid cancer, in particular, Bethesda classes, according to the histopathological examination. Category III TBSRTC is notable, usually in the case of adult patients classified for clinical observation; in our population, out of nine biopsies performed, thyroid cancer was detected in four cases $(44 \%)$ (Table 4 and Figure 8). 
The blood flow in the nodules in ultrasound imaging

$$
p=0.092
$$

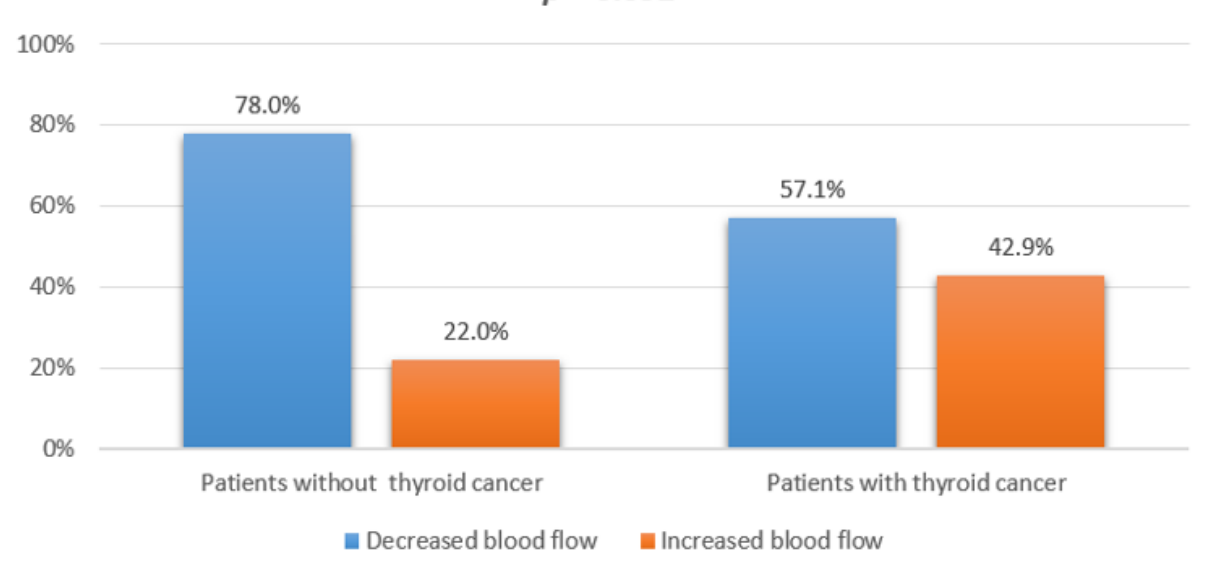

Figure 6. The blood flow in the nodules in ultrasound imaging.

\section{Percentage distribution of TBSRTC classes}

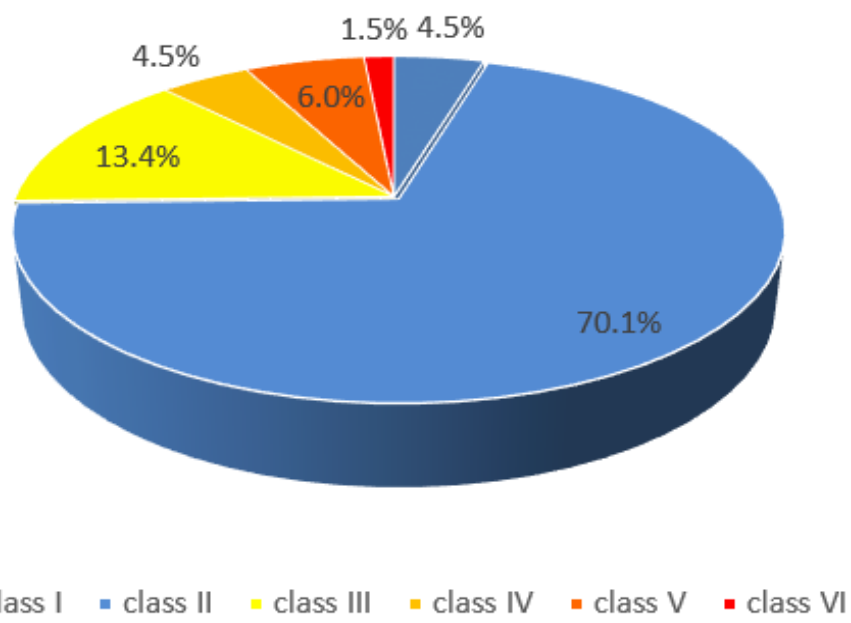

Figure 7. Percentage distribution of the TBSRTC (The Bethesda System for Reporting. Thyroid Cytopathology) classes.

Table 3. The final histopathologic diagnoses in children after FNAB. The three children with class I and 29 children with class II TBSRTC did not undergo surgery of the thyroid. TBSRTC (The Bethesda System for Reporting. Thyroid Cytopathology); AITD (autoimmunity thyroid diseases).

\begin{tabular}{|c|c|c|c|c|c|c|}
\hline TBSRTC & $\begin{array}{c}\text { AITD } \\
\text { (Hashimoto or } \\
\text { Graves' Disease) }\end{array}$ & $\begin{array}{l}\text { Multinodular } \\
\text { Goiter }\end{array}$ & $\begin{array}{l}\text { Benign Follicular } \\
\text { Nodule or Adenoma }\end{array}$ & $\begin{array}{l}\text { Papillary } \\
\text { Carcinoma }\end{array}$ & $\begin{array}{l}\text { Follicular } \\
\text { Carcinoma }\end{array}$ & $\begin{array}{l}\text { Poorly Differentiated } \\
\text { Thyroid Carcinoma }\end{array}$ \\
\hline I & 0 & 0 & 0 & 0 & 0 & 0 \\
\hline II & 0 & 1 & 13 & 2 & 0 & 0 \\
\hline III & 2 & 2 & 1 & 4 & 0 & 0 \\
\hline IV & 0 & 0 & 2 & 1 & 0 & 0 \\
\hline $\mathrm{V}$ & 0 & 0 & 0 & 1 & 3 & 0 \\
\hline VI & 0 & 0 & 0 & 0 & 0 & 1 \\
\hline
\end{tabular}


Table 4. The frequency of diagnosis of thyroid cancers in children in particular Bethesda classes.

\begin{tabular}{ccc}
\hline TBSRTC Class & $\begin{array}{c}\text { Number of Cancer Diagnoses of the } \\
\text { Number of Biopsies Performed }\end{array}$ & $\begin{array}{c}\text { Percentage of Children } \\
\text { Diagnosed with Cancer (\%) }\end{array}$ \\
\hline I & 0 out of 3 & 0 \\
\hline II & 2 out of 47 & 4 \\
\hline III & 4 out of 9 & 44 \\
\hline IV & 1 out of 3 & 33 \\
\hline V & 4 out of 4 & 100 \\
\hline VI & 1 out of 1 & 100 \\
\hline
\end{tabular}

\section{The frequency of diagnosis of thyroid cancers in children in particular Bethesda classes}

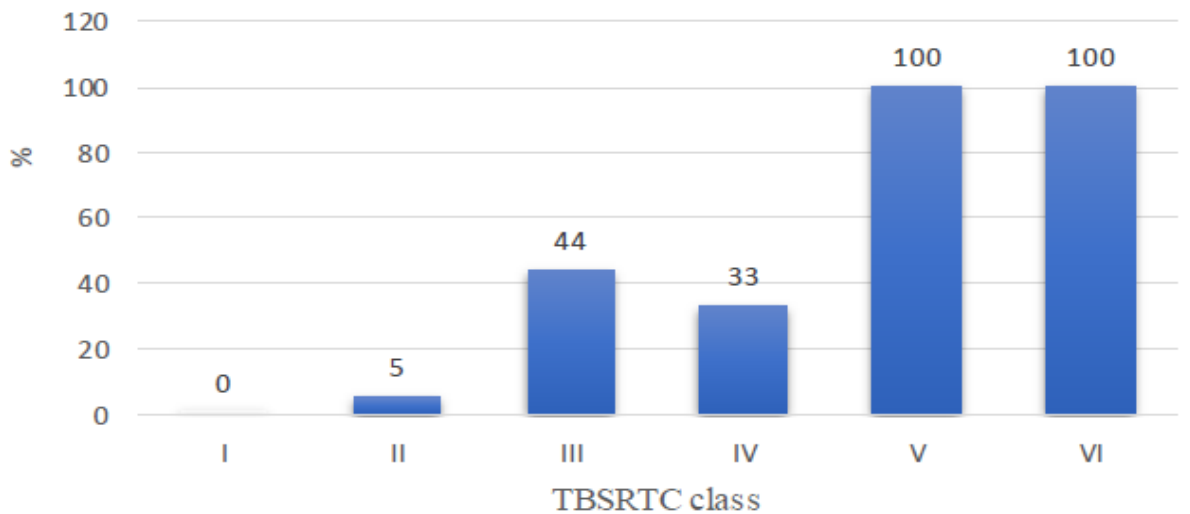

Figure 8. The frequency of diagnosis of thyroid cancers in children in particular Bethesda classes.

For each TBSRTC class, the relative risk of developing thyroid cancer was also calculated by comparing the incidence of thyroid cancer in categories III, IV, and V in combination with VI with the combined incidence in classes I and II.

For classes I and II, a total of 50 thyroid biopsies were performed, 3 and 47, respectively, with two thyroid cancer results. The incidence of thyroid cancer in class III TBSRTC was $44 \%$ (four patients), so the relative risk of developing thyroid cancer for class III was 11.1 times higher than that for classes I and II combined. The incidence of thyroid cancer in class IV TBSRTC was 33\% (three patients), so the relative risk of developing thyroid cancer for class IV was 8.3 times higher than that for classes I and II combined. The incidence of thyroid cancer in TBSRTC combined classes V and VI was one, so the relative risk of thyroid cancer for classes V and VI combined was 25 times higher than for classes I and II combined.

\section{Discussion}

Thyroid nodules are rare in the pediatric population, but often present a diagnostic and therapeutic challenge. According to the ATA guidelines, the Bethesda classification, which provides the basis for the development of treatment in adults, can also be used in children. However, according to our studies, there are significant differences that can have a considerable impact on the rapid and accurate diagnosis of pediatric patients. For this reason, in our work, we investigated the risk factors of thyroid cancer in children with thyroid nodules.

It is reported that those of female sex are at a higher risk of a nodular goiter unrelated to radiation sickness, but no significant relationship between the disease and the sex of the patients was found among the children studied [9]. Nevertheless, a large part of the study group was girls, who showed both a low and high risk of the disease. 
The thyroid gland in children is sensitive to radiation, which often causes nodules [2]. In our study, it was difficult to clearly define the risk of disease associated with exposure to radiation because only two patients had undergone radiation therapy due to previous cancer.

A more frequent occurrence of nodular goiter has also been observed in patients with a positive family history, Hashimoto's disease, and other thyroid diseases [3-6]. However, the analysis of the study group did not show a significant relationship between these risk factors and thyroid tumors.

Guidelines for the ultrasound diagnosis of thyroid nodules in adults are established and widely used [26,34-36]. However, it is debated whether the same guidelines can be applied to the pediatric population to effectively differentiate between benign and malignant lesions.

Over the last decade, differences in the risk stratification of thyroid nodules in pediatric ultrasound have been noted, which has resulted in the issuance of guidelines specifically for the pediatric population, such as the Assessment of the American College of Radiology (ACR) Thyroid Imaging Reporting and Data System (TI-RADS) and the update of the ATA guidelines [5,37,38]. Polat et al. analyzed the TI-RADS classification, and the results indicated its use is safe in children. However, the authors noted the small sample size and indicated that more research is needed on a larger group of children [39]. Regrettably, some other reports contradicted this conclusion and showed that the use of these guidelines in children carries a risk of missing cancer in up to $22 \%$ of pediatric patients $[38,40,41]$. The 2009 ATA guidelines recommended that the diagnostic criteria and treatment procedures for adults should also be used for the pediatric population [8].

Features of a focal thyroid lesion, such as being longer than wide, irregular margins or microcalcifications, always attract the examiner's attention and are an indisputable indication for a biopsy. However, regarding the remaining features detected in adult patients, doubts have recently been expressed about their utility in assessing the risk of nodular malignancy in children.

One of the questionable criteria is the size of the nodule. In adults, the nodule's size is not associated with increased malignancy risk, unlike in children. According to the 2018 Recommendation of Polish Scientific Societies Diagnostics and treatment of thyroid cancer, which coincide with the 2009 ATA guidelines for adults, changes below $1 \mathrm{~cm}$ in diameter visible on ultrasound do not require referral for FNAB, unless clinical examination or ultrasound finds features of an increased risk of malignancy, RET mutation, high levels of calcitonin, or no thyroid cancer metastases in a location other than the thyroid gland. However, lesions greater than $1 \mathrm{~cm}$ in diameter or detection of at least one of the previously mentioned criteria should be checked by FNAB [29]. Nonetheless, the criterion of the size of thyroid nodules in children is problematic because the size of the thyroid gland changes with age and the diameter of the nodule is not closely correlated with its potentially malignant nature. Therefore, guidelines specifically related to children were updated and announced in 2015 [5]. According to these guidelines, in children qualified for FNAB, the characteristic features in the ultrasound image and the clinical symptoms presented by the patient should be considered more than the size of the nodule. In our study, we found that children with a confirmed malignant nature of the lesion in histopathological examination had a greater height of the nodule. The cut-off point was $7 \mathrm{~mm}$, above which the risk of thyroid cancer was significantly greater. Suh et al. did not find a correlation with nodule size, whereas Gannon et al. reported an increased risk of neoplasm with a size of $\geq 1 \mathrm{~cm}[1,42]$. Richman et al. detected that the malignancy rate increased with increasing nodule size, but without a cut-off point [24].

The hypoechoic nature of the lesion is another controversial parameter among the authors of related publications around the world. In our work, hypoechoic changes in US correlated with an increased risk of malignant lesion diagnosis $(p=0.010)$. In the group of children diagnosed with cancer, this change occurred more often than in the group of children diagnosed with benign changes. The lesion was hypoechoic in $78.6 \%$ of children diagnosed with thyroid cancer. However, it cannot be ignored that $41.8 \%$ of the hypoechoic 
lesions in the US study were later found to be benign. Our data were in the range of $30-55 \%$ for benign lesions and $71-92 \%$ for malignant lesions obtained in a previous study [23]. The discrepancy in the sensitivity of this parameter between studies is significant. It varies between $26 \%$ and $41 \%$ and between $50.9 \%$ and $75.9 \%$, suggesting that the importance of hypoechogenicity as a criterion for the malignancy of the lesion should be diminished, but it cannot be completely ignored $[19,24,25,38]$.

Increased tumor vascularization is a recognized risk factor of malignancy and an indication for further diagnosis [5,43]. Unfortunately, several new findings have been published that contradict this approach $[1,24,42,44]$. Lingam et al. found that central or mixed color Doppler flow pattern and significant hypoechogenicity lead mostly to false-positive results [44]. In our children group, no statistically significant relationship was found between the presence of increased blood flow in the vessels and the diagnosis of thyroid cancer $(p=0.092)$, in line with new literature data. These conclusions do not allow for unequivocal differentiation of malignant lesions on the basis of vascularization, although the US Doppler test still remains useful in the clinical context, for example, to prevent damage to the vascular cluster during FNAB or to differentiate focal lesions from a cyst or blood clot [45].

Despite many attempts, so far, no one has managed to clearly establish the characteristics of malignant thyroid lesions in the pediatric population that we could safely use in clinical practice. We believe that it is necessary to conduct a large study, involving cooperation with other research centers.

Perhaps training in the performance of elastography will contribute to the wider dissemination of this examination and its inclusion in the permanent diagnostic algorithm of thyroid nodules in children. So far, little such research has been conducted, although the conclusions that elastography is a suitable complementary study and the high elasticity of a nodule in elastography is associated with a low risk of thyroid cancer are encouraging [46,47].

Fine needle aspiration biopsy was reported to have a very high sensitivity of $95 \%$, a specificity of $86 \%$, and an accuracy of $90 \%$; however, in our study, they were lower than in other studies (sensitivity of $67 \%$ and specificity of $90.2 \%$ ) $[6,48]$. FNAB is also a relatively cheap test. This examination is ideal for assessing thyroid nodules because of its properties and the use of TBSRTC.

TBSRTC has been widely used in the reporting of thyroid cytopathology and has allowed the nomenclature to be standardized around the world. The Bethesda classification has also facilitated therapeutic decisions, allowing for a more reliable comparison of statistical data, which improved the therapy of thyroid tumors.

Since the introduction of the TBSRTC in 2009, it has undergone some modifications to improve the system, e.g., reclassification of the noninvasive encapsulated follicular variant of papillary thyroid carcinoma (EFVPTC) in noninvasive follicular thyroid neoplasm with papillary-like nuclear features (NIFTP), which was aimed at reducing ROM and surgical overtreatment of benign lesions [49-51].

Sauter et al. focused on the problem of the overdiagnosis and overtreatment of benign thyroid nodules, while emphasizing the difficulties faced by clinicians in assessing the risk of Bethesda class III and IV malignancies. Using long-term clinical follow-up data, they showed more accurate positive and negative predictive values of diagnostic categories, reducing the overdiagnosis of AUS/FLUS, but maintaining high efficiency in the diagnosis of malignant and benign tumors. Thus, they indicated the role of pathologists who, by limiting the use of intermediate Bethesda classification categories (AUS/FLUS), if possible, could facilitate therapeutic decision making for clinicians [51].

The risk of malignancy of tumors in classes III, V, and VI has been confirmed by numerous studies, and the choice of clinical procedure is not difficult, e.g., ATA guidelines can be used. Benign lesions (class II) are further assessed with US and FNAB, and molecular tests are performed; only in some cases is surgical treatment used. In the case of lesions highly suspected of being malignant or confirmed malignant (classes V and VI), surgery 
is the treatment of choice $[5,33,36,52]$. Problems with treatment choice for the intermediate classes of TBSRTC (classes III and IV) has already been addressed in several studies [49,52,53].

Both classes III and IV have an intermediate risk of malignancy: $6-30 \%$ and $10-40 \%$, respectively [33]. The risk is so high that choosing the right therapy tailored to a specific patient is difficult and can easily be affected by errors. All these problems require work to adapt the Bethesda system to assess children with thyroid tumors, which can be achieved by planning and analyzing statistical studies in the pediatric population.

According to our observations, Bethesda system class III in children may already be a risk factor of malignant thyroid neoplasm, whereas in adults, the risk of malignancy increases significantly in Bethesda class IV, as reported in other studies [1,2,6,10]. Sources report that the risk of malignancy in classes V and VI is $100 \%$, which is confirmed by our results [10].

Regarding adult patients with undefined preoperative thyroid cytopathology, surgery is only performed after re-biopsy or molecular tests. In children, the guidelines are more radical, and surgery is recommended after the first biopsy [10,54].

The more aggressive treatments in children are due to their longer life expectancy. In children, genetic predisposition to the development of thyroid neoplasms is more common. One must also consider the increased influence of growth factors, especially increased insulin-like growth factor-1 (IGF-1) in childhood and adolescence. The IGF complex seems to play an important role in thyroid cancer. The expression of the IGF-1 system is enhanced in thyroid cancer (especially in PTC) compared to other thyroid diseases [55].

\section{Conclusions}

The thyroid cancer risk was significantly increased in children with a nodule height greater than $7 \mathrm{~mm}$ and with a hypoechogenic structure in ultrasonography.

TBSRTC is effective for the qualification of children for surgery of the thyroid. Approximately $25 \%$ of FNAB in children with nodular goiter were qualified to classes III and VI of the TBSRTC. Class III TBSRTC was connected in our pediatric with a higher risk of thyroid cancer in comparison to the adult population. Classes III and VI should be an indication for partial or total thyroidectomy because of the significantly high risk of thyroid cancer.

Author Contributions: Conceptualization, I.B.-S., J.S., P.N.; methodology, I.B.-S., J.S.; software, I.B.-S., E.P., W.W.; validation, I.B.-S., J.S., P.N.; formal analysis, I.B.-S., J.S.; investigation, I.B.-S., J.S., A.M., M.M. (Magdalena Makuch), M.M. (Magdalena Malka), C.C., P.N.; resources I.B.-S., J.S.; data curation, I.B.-S., J.S., E.P., W.W., A.S., Z.T., A.S., M.M. (Magdalena Makuch), M.M. (Magdalena Malka); writingoriginal draft preparation, I.B.-S., J.S., E.P., W.W., A.S., Z.T., A.S.; writing-review and editing, I.B.-S., J.S., E.P.,W.W., A.S., Z.T., A.S.; visualization, I.B.-S., J.S., E.P.,W.W., A.S., Z.T., A.S.; supervision, I.B.-S.; project administration, I.B.-S., J.S.; funding acquisition, I.B.-S. All authors have read and agreed to the published version of the manuscript.

Funding: This research was funded by Medical University in Lublin, Poland, grant number 415.

Institutional Review Board Statement: The study was conducted according to the guidelines of the Declaration of Helsinki, and approved by the Ethics Committee of Medical University in Lublin, Poland (protocol code KE-0254/24/2020 and date of approval 28 January 2020.

Informed Consent Statement: Written informed consent has been obtained from the parents of the patients to publish this paper.

Data Availability Statement: Data Availability Statements in section University Children Hospital in Lublin Poland.

Acknowledgments: We acknowledge Maria Sobol from Medical University in Warsaw for the help in statistic analyze.

Conflicts of Interest: The authors declare no conflict of interest. 


\section{References}

1. Suh, J.; Choi, H.S.; Kwon, A.; Chae, H.W.; Kim, H.-S. Adolescents with thyroid nodules: Retrospective analysis of factors predicting malignancy. Eur. J. Pediatr. 2020, 179, 317-325. [CrossRef]

2. Iakovou, I.; Giannoula, E.; Sachpekidis, C. Imaging and Imaging-Based Management of Pediatric Thyroid Nodules. J. Clin. Med. 2020, 9, 384. [CrossRef]

3. Al Nofal, A.; Gionfriddo, M.R.; Javed, A.; Haydour, Q.; Brito, J.P.; Prokop, L.J.; Pittock, S.T.; Murad, M.H. Accuracy of thyroid nodule sonography for the detection of thyroid cancer in children: Systematic review and meta-analysis. Clin. Endocrinol. 2016, 84, 423-430. [CrossRef]

4. Bauer, A.J. Pediatric Thyroid Cancer: Genetics, Therapeutics and Outcome. Endocrinol. Metab. Clin. N. Am. 2020, 49, 589-611. [CrossRef]

5. Francis, G.L.; Waguespack, S.G.; Bauer, A.J.; Angelos, P.; Benvenga, S.; Cerutti, J.M.; Dinauer, C.A.; Hamilton, J.; Hay, I.D.; Luster, M.; et al. Management Guidelines for Children with Thyroid Nodules and Differentiated Thyroid Cancer. Thyroid 2015, 25, 716-759. [CrossRef]

6. Paulson, V.A.; Rudzinski, E.R.; Hawkins, D.S. Thyroid Cancer in the Pediatric Population. Genes 2019, 10, 723. [CrossRef]

7. Drozd, V.; Saenko, V.; Branovan, D.I.; Brown, K.; Yamashita, S.; Reiners, C. A Search for Causes of Rising Incidence of Differentiated Thyroid Cancer in Children and Adolescents after Chernobyl and Fukushima: Comparison of the Clinical Features and Their Relevance for Treatment and Prognosis. Int. J. Environ. Res. Public Health 2021, 18, 3444. [CrossRef]

8. Cooper, D.S.; Doherty, G.M.; Haugen, B.R.; Hauger, B.R.; Kloos, R.T.; Lee, S.L.; Mandel, S.J.; Mazzaferri, E.L.; McIver, B.; Pacini, F.; et al. Revised American Thyroid Association management guidelines for patients with thyroid nodules and differentiated thyroid cancer. Thyroid 2009, 19, 1167-1214. [CrossRef]

9. Stack, B.C.; Twining, C.; Rastatter, J.; Angelos, P.; Baloch, Z.; Diercks, G.; Faquin, W.; Kazahaya, K.; Rivkees, S.; Sheyn, T.; et al. Consensus statement by the American Association of Clinical Endocrinology (AACE) and the American Head and Neck Society Endocrine Surgery Section (AHNS-ES) on Pediatric Benign and Malignant Thyroid Surgery. Head Neck 2021, 43, 1027-1042. [CrossRef]

10. Szmit-Domagalska, J.; Horodnicka-Józwa, A.; Petriczko, E.; Biczysko-Mokosa, A.; Marcinkiewicz, K.; Walczak, M. Rak brodawkowaty tarczycy u trójki dzieci. Pediatr. Endocrinol. Diabetes Metab. 2019, 25, 202-207. [CrossRef]

11. Skubisz, K.; Januszkiewicz-Caulier, J.; Cybula, P.; Bakuła-Zalewska, E.; Goryca, K.; Paziewska, A.; Ambrożkiewicz, F.; Woliński, K.; Mikula, M.; Ostrowski, J.; et al. Higher EU-TIRADS-Score Correlated with BRAF V600E Positivity in the Early Stage of Papillary Thyroid Carcinoma. J. Clin. Med. 2021, 10, 2304. [CrossRef]

12. Abdullah, M.I.; Junit, S.M.; Ng, K.L.; Jayapalan, J.J.; Karikalan, B.; Hashim, O.H. Papillary Thyroid Cancer: Genetic Alterations and Molecular Biomarker Investigations. Int. J. Med. Sci. 2019, 16, 450-460. [CrossRef]

13. Tirrò, E.; Martorana, F.; Romano, C.; Vitale, S.R.; Motta, G.; Di Gregorio, S.; Massimino, M.; Pennisi, M.S.; Stella, S.; Puma, A.; et al Molecular Alterations in Thyroid Cancer: From Bench to Clinical Practice. Genes 2019, 10, 709. [CrossRef]

14. Song, Y.S.; Park, Y.J. Genomic Characterization of Differentiated Thyroid Carcinoma. Endocrinol. Metab. 2019, 34, 1-10. [CrossRef]

15. Prete, A.; Borges de Souza, P.; Censi, S.; Muzza, M.; Nucci, N.; Sponziello, M. Update on Fundamental Mechanisms of Thyroid Cancer. Front. Endocrinol. 2020, 11, 102. [CrossRef]

16. Rangel-Pozzo, A.; Sisdelli, L.; Cordioli, M.I.V.; Vaisman, F.; Caria, P.; Mai, S.; Cerutti, J.M. Genetic Landscape of Papillary Thyroid Carcinoma and Nuclear Architecture: An Overview Comparing Pediatric and Adult Populations. Cancers 2020, $12,3146$. [CrossRef]

17. Mitsutake, N.; Saenko, V. Molecular pathogenesis of pediatric thyroid carcinoma. J. Radiat. Res. 2021, 62, i71-i77. [CrossRef]

18. Accardo, G.; Conzo, G.; Esposito, D.; Gambardella, C.; Mazzella, M.; Castaldo, F.; Di Donna, C.; Polistena, A.; Avenia, N.; Colantuoni, V.; et al. Genetics of medullary thyroid cancer: An overview. Int. J. Surg. 2017, 41 (Suppl. 1), S2-S6. [CrossRef]

19. Corrias, A.; Mussa, A. Thyroid nodules in pediatrics: Which ones can be left alone, which ones must be investigated, when and how. J. Clin. Res. Pediatr. Endocrinol. 2013, 5 (Suppl. 1), 57-69. [CrossRef]

20. Guille, J.T.; Opoku-Boateng, A.; Thibeault, S.L.; Chen, H. Evaluation and management of the pediatric thyroid nodule. Oncologist 2015, 20, 19-27. [CrossRef]

21. Sohn, Y.-M.; Kwak, J.Y.; Kim, E.-K.; Moon, H.J.; Kim, S.J.; Kim, M.J. Diagnostic approach for evaluation of lymph node metastasis from thyroid cancer using ultrasound and fine-needle aspiration biopsy. AJR Am. J. Roentgenol. 2010, 194, 38-43. [CrossRef]

22. Koltin, D.; O'Gorman, C.S.; Murphy, A.; Ngan, B.; Daneman, A.; Navarro, O.M.; García, C.; Atenafu, E.G.; Wasserman, J.D.; Hamilton, J.; et al. Pediatric thyroid nodules: Ultrasonographic characteristics and inter-observer variability in prediction of malignancy. J. Pediatr. Endocrinol. Metab. 2016, 29, 789-794. [CrossRef]

23. Anil, G.; Hegde, A.; Chong, F.H.V. Thyroid nodules: Risk stratification for malignancy with ultrasound and guided biopsy. Cancer Imaging 2011, 11, 209-223. [CrossRef]

24. Richman, D.M.; Benson, C.B.; Doubilet, P.M.; Peters, H.E.; Huang, S.A.; Asch, E.; Wassner, A.J.; Smith, J.R.; Cherella, C.E.; Frates, M.C. Thyroid Nodules in Pediatric Patients: Sonographic Characteristics and Likelihood of Cancer. Radiology 2018, 288, 591-599. [CrossRef]

25. Mussa, A.; de Andrea, M.; Motta, M.; Mormile, A.; Palestini, N.; Corrias, A. Predictors of Malignancy in Children with Thyroid Nodules. J. Pediatr. 2015, 167, 886-892.e1. [CrossRef] 
26. Russ, G.; Bonnema, S.J.; Erdogan, M.F.; Durante, C.; Ngu, R.; Leenhardt, L. European Thyroid Association Guidelines for Ultrasound Malignancy Risk Stratification of Thyroid Nodules in Adults: The EU-TIRADS. Eur. Thyroid J. 2017, 6, $225-237$. [CrossRef]

27. Gupta, A.; Ly, S.; Castroneves, L.A.; Frates, M.C.; Benson, C.B.; Feldman, H.A.; Wassner, A.J.; Smith, J.R.; Marqusee, E.; Alexander, E.K.; et al. A standardized assessment of thyroid nodules in children confirms higher cancer prevalence than in adults. J. Clin. Endocrinol. Metab. 2013, 98, 3238-3245. [CrossRef]

28. Bossowski, A. Diagnostyka i Leczenie Chorób Tarczycy Dzieci i Młodzieży; Medical Tribune Polska: Warszawa, Poland, 2020; ISBN 9788395667763.

29. Jarząb, B.; Dedecjus, M.; Słowińska-Klencka, D.; Lewiński, A.; Adamczewski, Z.; Anielski, R.; Bagłaj, M.; Bałdys-Waligórska, A.; Barczyński, M.; Bednarczuk, T.; et al. Guidelines of Polish National Societies Diagnostics and Treatment of Thyroid Carcinoma. 2018 Update. Endokrynol. Pol. 2018, 69, 34-74. [CrossRef]

30. Niedziela, M. Thyroid nodules. Best Pract. Res. Clin. Endocrinol. Metab. 2014, 28, 245-277. [CrossRef]

31. Wells, S.A.; Asa, S.L.; Dralle, H.; Elisei, R.; Evans, D.B.; Gagel, R.F.; Lee, N.; Machens, A.; Moley, J.F.; Pacini, F.; et al. Revised American Thyroid Association guidelines for the management of medullary thyroid carcinoma. Thyroid 2015, 25, 567-610. [CrossRef]

32. Heider, A.; Arnold, S.; Jing, X. Bethesda System for Reporting Thyroid Cytopathology in Pediatric Thyroid Nodules: Experience of a Tertiary Care Referral Center. Arch. Pathol. Lab. Med. 2020, 144, 473-477. [CrossRef]

33. Cibas, E.S.; Ali, S.Z. The 2017 Bethesda System for Reporting Thyroid Cytopathology. Thyroid 2017, 27, 1341-1346. [CrossRef]

34. Tessler, F.N.; Middleton, W.D.; Grant, E.G.; Hoang, J.K.; Berland, L.L.; Teefey, S.A.; Cronan, J.J.; Beland, M.D.; Desser, T.S.; Frates, M.C.; et al. ACR Thyroid Imaging, Reporting and Data System (TI-RADS): White Paper of the ACR TI-RADS Committee. J. Am. Coll. Radiol. 2017, 14, 587-595. [CrossRef]

35. Weller, A.; Sharif, B.; Qarib, M.H.; St Leger, D.; de Silva, H.S.; Lingam, R.K. British Thyroid Association 2014 classification ultrasound scoring of thyroid nodules in predicting malignancy: Diagnostic performance and inter-observer agreement. Ultrasound 2020, 28, 4-13. [CrossRef]

36. Haugen, B.R.; Alexander, E.K.; Bible, K.C.; Doherty, G.M.; Mandel, S.J.; Nikiforov, Y.E.; Pacini, F.; Randolph, G.W.; Sawka, A.M.; Schlumberger, M.; et al. 2015 American Thyroid Association Management Guidelines for Adult Patients with Thyroid Nodules and Differentiated Thyroid Cancer: The American Thyroid Association Guidelines Task Force on Thyroid Nodules and Differentiated Thyroid Cancer. Thyroid 2016, 26, 1-133. [CrossRef]

37. Lim-Dunham, J.E. Ultrasound guidelines for pediatric thyroid nodules: Proceeding with caution. Pediatr. Radiol. 2019, 49, 851-853. [CrossRef]

38. Richman, D.M.; Benson, C.B.; Doubilet, P.M.; Wassner, A.J.; Asch, E.; Cherella, C.E.; Smith, J.R.; Frates, M.C. Assessment of American College of Radiology Thyroid Imaging Reporting and Data System (TI-RADS) for Pediatric Thyroid Nodules. Radiology 2020, 294, 415-420. [CrossRef]

39. Polat, Y.D.; Öztürk, V.S.; Ersoz, N.; Anık, A.; Karaman, C.Z. Is Thyroid Imaging Reporting and Data System Useful as an Adult Ultrasonographic Malignancy Risk Stratification Method in Pediatric Thyroid Nodules? J. Med. Ultrasound 2019, 27, 141-145. [CrossRef]

40. Martinez-Rios, C.; Daneman, A.; Bajno, L.; van der Kaay, D.C.M.; Moineddin, R.; Wasserman, J.D. Utility of adult-based ultrasound malignancy risk stratifications in pediatric thyroid nodules. Pediatr. Radiol. 2018, 48, 74-84. [CrossRef]

41. Creo, A.; Alahdab, F.; Al Nofal, A.; Thomas, K.; Kolbe, A.; Pittock, S.T. Ultrasonography and the American Thyroid Association Ultrasound-Based Risk Stratification Tool: Utility in Pediatric and Adolescent Thyroid Nodules. Horm. Res. Paediatr. 2018, 90, 93-101. [CrossRef]

42. Gannon, A.W.; Langer, J.E.; Bellah, R.; Ratcliffe, S.; Pizza, J.; Mostoufi-Moab, S.; Cappola, A.R.; Bauer, A.J. Diagnostic Accuracy of Ultrasound With Color Flow Doppler in Children With Thyroid Nodules. J. Clin. Endocrinol. Metab. 2018, 103, 1958-1965. [CrossRef]

43. Lyshchik, A.; Drozd, V.; Demidchik, Y.; Reiners, C. Diagnosis of thyroid cancer in children: Value of gray-scale and power doppler US. Radiology 2005, 235, 604-613. [CrossRef]

44. Lingam, R.K.; Qarib, M.H.; Tolley, N.S. Evaluating thyroid nodules: Predicting and selecting malignant nodules for fine-needle aspiration (FNA) cytology. Insights Imaging 2013, 4, 617-624. [CrossRef]

45. Essenmacher, A.C.; Joyce, P.H.; Kao, S.C.; Epelman, M.; Pesce, L.M.; D’Alessandro, M.P.; Sato, Y.; Johnson, C.M.; Podberesky, D.J Sonographic Evaluation of Pediatric Thyroid Nodules. Radiographics 2017, 37, 1731-1752. [CrossRef]

46. Borysewicz-Sanczyk, H.; Dzieciol, J.; Sawicka, B.; Bossowski, A. Practical Application of Elastography in the Diagnosis of Thyroid Nodules in Children and Adolescents. Horm. Res. Paediatr. 2016, 86, 39-44. [CrossRef]

47. Cunha, G.B.; Marino, L.C.I.; Yamaya, A.; Kochi, C.; Monte, O.; Longui, C.A.; Cury, A.N.; Fleury, E.D.F.C. Elastography for the evaluation of thyroid nodules in pediatric patients. Radiol. Bras. 2019, 52, 141-147. [CrossRef]

48. Ahmad, H.; Al-Hadidi, A.; Bobbey, A.; Shah, S.; Stanek, J.; Nicol, K.; Hoffman, R.P.; Aldrink, J.H. Pediatric adaptions are needed to improve the diagnostic accuracy of thyroid ultrasound using TI-RADS. J. Pediatr. Surg. 2021, 56, 1120-1125. [CrossRef]

49. Kaliszewski, K.; Diakowska, D.; Wojtczak, B.; Sutkowski, K.; Knychalski, B.; Forkasiewicz, Z. Patients with III and IV category of the Bethesda System under levothyroxine non-suppressive therapy have a lower rate of thyroid malignancy. Sci. Rep. 2019, 9, 8409. [CrossRef] 
50. Zhu, Y.; Song, Y.; Xu, G.; Fan, Z.; Ren, W. The Bethesda System for Reporting Thyroid Cytopathology (TBSRTC): A report of 2781 cases in a Chinese population. Chin. J. Cancer Res. 2020, 32, 140-148. [CrossRef]

51. Sauter, J.L.; Lehrke, H.; Zhang, X.; Al Badri, O.T.; Rodriguez-Gutierrez, R.; Delivanis, D.A.; Singh Ospina, N.; Donegan, D.; Hamidi, O.; Iñiguez-Ariza, N.; et al. Assessment of The Bethesda System for Reporting Thyroid Cytopathology. Am. J. Clin. Pathol. 2019, 152, 502-511. [CrossRef]

52. Yaprak Bayrak, B.; Eruyar, A.T. Malignancy rates for Bethesda III and IV thyroid nodules: A retrospective study of the correlation between fine-needle aspiration cytology and histopathology. BMC Endocr. Disord. 2020, 20, 48. [CrossRef] [PubMed]

53. Alshaikh, S.; Harb, Z.; Aljufairi, E.; Almahari, S.A. Classification of thyroid fine-needle aspiration cytology into Bethesda categories: An institutional experience and review of the literature. Cytojournal 2018, 15, 4. [CrossRef] [PubMed]

54. Wang, H.; Mehrad, M.; Ely, K.A.; Liang, J.; Solórzano, C.C.; Neblett, W.W.; Coogan, A.C.; Weiss, V.L. Incidence and malignancy rates of indeterminate pediatric thyroid nodules. Cancer Cytopathol. 2019, 127, 231-239. [CrossRef] [PubMed]

55. Karagiannis, A.; Kassi, E.; Chatzigeorgiou, A.; Koutsilieris, M. IGF Bioregulation System in Benign and Malignant Thyroid Nodular Disease: A Systematic Review. In Vivo 2020, 34, 3069-3091. [CrossRef] [PubMed] 